\title{
Identificación de factores esenciales para la creación de empresas desde la perspectiva del emprendedor: el caso del Parque del Emprendimiento
}

\author{
Identification of essential factors for the creation of companies from the perspective of the entrepreneur: the case of \\ the Entrepreneurship Park \\ Identificação de fatores essenciais para a criação de empresas sob a perspectiva do empreendedor: o caso do Parque do \\ Empreendedorismo
}

Jhon Jaime Arango Benjumea a

Universidad Cooperativa de Colombia, Colombia

jhon.arangob@campusucc.edu.co

ORCID: http://orcid.org/0000-0002-4036-3178

DOI: https://doi.org/10.11144/Javeriana.cc18-45.ifec

\section{Resumen:}

El emprendimiento es un modelo social y económico que tiene como propósito impulsar la creación de empresas. Montar un negocio no es emprendimiento. Se requiere de un producto, un servicio o un proceso innovador para que una iniciativa empresarial pueda ser catalogada como un verdadero emprendimiento. Por medio de la identificación de factores relevantes, se puede definir el emprendimiento como la iniciativa personal de idear, montar y poner en marcha una nueva empresa. Para lograr este propósito, se requiere de educación, persistencia, motivación, contactos, habilidades en mercadeo y recursos de capital, así como de apoyo del Estado, de la familia y de la universidad, en un contexto en el que se afrontan riesgos y dificultades tales como el desánimo y la soledad. El espíritu empresarial es la fuerza interior del emprendedor que lo impulsa a lograr el objetivo de materializar su sueño de ser independiente económicamente, mediante la creación y puesta en marcha de su propia nueva empresa.

Palabras clave: Emprendimiento, emprendedor, espíritu empresarial, proceso de empresa.

\section{Abstract:}

Entrepreneurship is a social and economic model that aims to promote the creation of companies. Setting up a business is not entrepreneurship. It requires a product, a service, or an innovative process so that a business initiative can be cataloged as real entrepreneurship. Through the identification of relevant factors, entrepreneurship can be defined as the personal initiative to devise, assemble, and start up a new company. To achieve this purpose, education, persistence, motivation, contacts, marketing skills, and capital resources are required, as well as support from the State, family, and the university, in a context where risks and difficulties such as discouragement and loneliness are faced. The entrepreneurial spirit is the inner strength of the entrepreneur that drives him to achieve the goal of materializing his dream of being economically independent through the creation and start-up of his own new company.

Keywords: Entrepreneurship, entrepreneur, entrepreneurship spirit, business process.

\section{Resumo:}

O empreendedorismo é um modelo social e econômico que tem como propósito impulsionar a criação de empresas. Estabelecer um negócio não é empreendedorismo. Requer-se de um produto, um serviço ou um processo inovador para uma iniciativa empresarial puder ser catalogada como verdadeiro empreendedorismo. Por meio da identificação de fatores relevantes, pode se definir o empreendedorismo como a iniciativa pessoal de idear, montar e por em marcha uma nova empresa. Para atingir tal objetivo é preciso educação, persistência, motivação, contatos, habilidades em mercadejo e recursos de capital, bem como apoio do Estado, da família e da universidade, em um contexto em que riscos e dificuldades tais como desânimo e soledade são enfrentados. $\mathrm{O}$ espírito empresarial é a força interior do empreendedor que o impulsiona a conseguir o objetivo de materializar seu sonho de ser independente economicamente, mediante a criação e posta em marcha da sua própria nova empresa.

Palavras-chave: Empreendedorismo, empreendedor, espírito empresarial, processo de empresa.

Notas de autor 


\section{Introducción}

Desde épocas recientes, el emprendimiento se ha venido perfilando como la base del desarrollo y del crecimiento económico de las regiones, debido a que tiene como propósito la renovación y el fortalecimiento del tejido empresarial y social. Desde diversos enfoques, los programas de emprendimiento empresarial han centrado sus esfuerzos en la formación: sus puntos de partida y de desarrollo principales han sido, respectivamente, la sensibilización, y la capacitación para la gestación de ideas y planes de negocio; requisitos previos para la creación y puesta en marcha de las nuevas empresas. En comparación con el número de personas que son motivadas y capacitadas en materia de ideas y planes de negocio, son pocos los emprendedores que logran crear y poner en marcha una nueva empresa. En ese contexto, es pertinente plantearse algunos interrogantes como ¿qué pasa desde el momento en que surgen los planes de negocio hasta la creación de nuevas empresas?, y ¿qué dificultades tienen los emprendedores para seguir adelante con sus iniciativas empresariales?, entre otras indagaciones de similares connotaciones. Dar respuesta a estos interrogantes es el interés que motiva la identificación de los aspectos esenciales para la creación de empresas.

\section{El Parque del Emprendimiento y algunos aspectos esenciales del estudio}

El Parque del Emprendimiento, o Parque E, nace como una iniciativa de la Universidad de Antioquia y la Alcaldía de Medellín. Este proyecto busca promover y fortalecer la cultura del emprendimiento mediante el apoyo a la creación de empresas a partir de oportunidades de negocio, resultados de investigación y actividades académicas. Con el fin de cumplir con dicho propósito se ha diseñado un programa de apoyo a la creación de empresas que consta de las fases de planeación, puesta en marcha y consolidación. En primer lugar, el objetivo de la etapa de planeación es apoyar la identificación de ideas de negocio con viabilidad empresarial, así como la posterior elaboración del plan de negocios. El objetivo de la fase de puesta en marcha es apoyar al emprendedor que tiene un modelo de negocios definido, o que cuenta con un prototipo o un pilotaje desarrollado, mediante un acercamiento comercial o, en su defecto, con un plan de negocios estructurado. Por último, el objetivo de la etapa de consolidación es dar apoyo a empresas ya formalizadas y que cuentan con actividad comercial constante en los últimos seis meses.

\section{Perspectiva teórica}

El término emprendedor se deriva de la voz castellana emprender. Esta proviene a su vez de los vocablos latinos in, en, y prendère, y significa acometer o comenzar una obra, un negocio, especialmente si las actividades involucradas suponen dificultad o peligro (RAE, 2012). Emprendedor fue definida por primera vez en el Diccionario de Autoridades ${ }^{1}$ de 1732 como la persona que emprende y se determina a hacer o ejecutar, con resolución y empeño, alguna operación considerable y ardua.

A principios de Siglo XVI, se utilizó en Francia el vocablo entrepreneur para designar a los aventureros que se arriesgaban a explorar el nuevo mundo en busca de mejores oportunidades, sin saber qué les depararía el futuro. El término también fue asociado con militares expedicionarios, constructores de vías terrestres y arquitectos. Por su parte, el vocablo emprendedor ha sido relacionado en la actualidad con la voluntad o capacidad que tiene un individuo para enfrentar la incertidumbre. No obstante, el emprendedor asume riesgos con la esperanza de obtener una recompensa en el futuro ( Brunet \& Alarcón, 2004; Morales \& Segoviano, 2016). De acuerdo esta concepción, en la actualidad el emprendedor deja de ser un tomador de contratos para convertirse en un tomador de riesgos. 
De acuerdo con la concepción clásica, el emprendimiento se desarrolla con base en las acciones de un agente que utiliza los medios de producción para fabricar nuevos productos, a pesar del riesgo y de la incertidumbre ante la ocurrencia de eventos futuros desconocidos (Brunet \& Alarcón, 2004; Tarapuez, Zapata \& Agrenda, 2008; Valenciano \& Uribe, 2009). Este agente es un líder, un previsor y un evaluador de proyectos, que moviliza recursos desde una zona de bajo rendimiento hasta una de alta productividad. De acuerdo con la concepción contemporánea del término, el emprendedor se perfilaría como un agente innovador y dinamizador del desarrollo económico y social. Al no estar motivado solamente por las ganancias, el emprendedor es capaz de suscitar innovaciones y cambios que modifican profundamente la sociedad.

De acuerdo con el estudio de Formichella (2002), Schumpeter (1942, citado en Formichella, 2002) y Drucker (1985, citado en Formichella, 2002) coinciden en que el emprendedor es un individuo fuera de lo común pues promueve innovaciones; alguien cuyas acciones causan cambios en la sociedad y en los mercados. Los emprendedores propician la innovación, que es el elemento central del crecimiento económico y, por ende, del desarrollo social. Si bien el emprendimiento se puede enseñar y aprender, las personas que necesitan ver sus certezas confirmadas constantemente no poseen condiciones para ser emprendedoras (Drucker y Maciariello, 1954; Drucker, 1985, citado en Formichella, 2002; Varela, 2001).

El efecto esperado de una iniciativa de emprendimiento es la creación de una nueva empresa, la cual obedece a un proceso dinámico que implica una permanente realimentación en sus componentes y variables (Brunet \& Alarcón, 2004). Esto es lo que Kirzner (1998) denomina el elemento empresarial, aspecto que relaciona con toda acción humana que está presente en la actividad económica: un rasgo que, con todo, no se puede analizar en términos de economía, maximización o con criterios de eficiencia. Como bien lo compila Varela (2001), para Shapero (1975, citado en Varela, 2001), la creación de empresas es el resultado final de una acción humana muy especial y el comienzo de otra. En esta misma línea, Ronstadt (1983, citado en Varela, 2001) arguye que crear empresas es un proceso elaborado en torno a pensamientos y acciones: una dinámica que va más allá de una idea, de un proyecto y del mismo empresario.

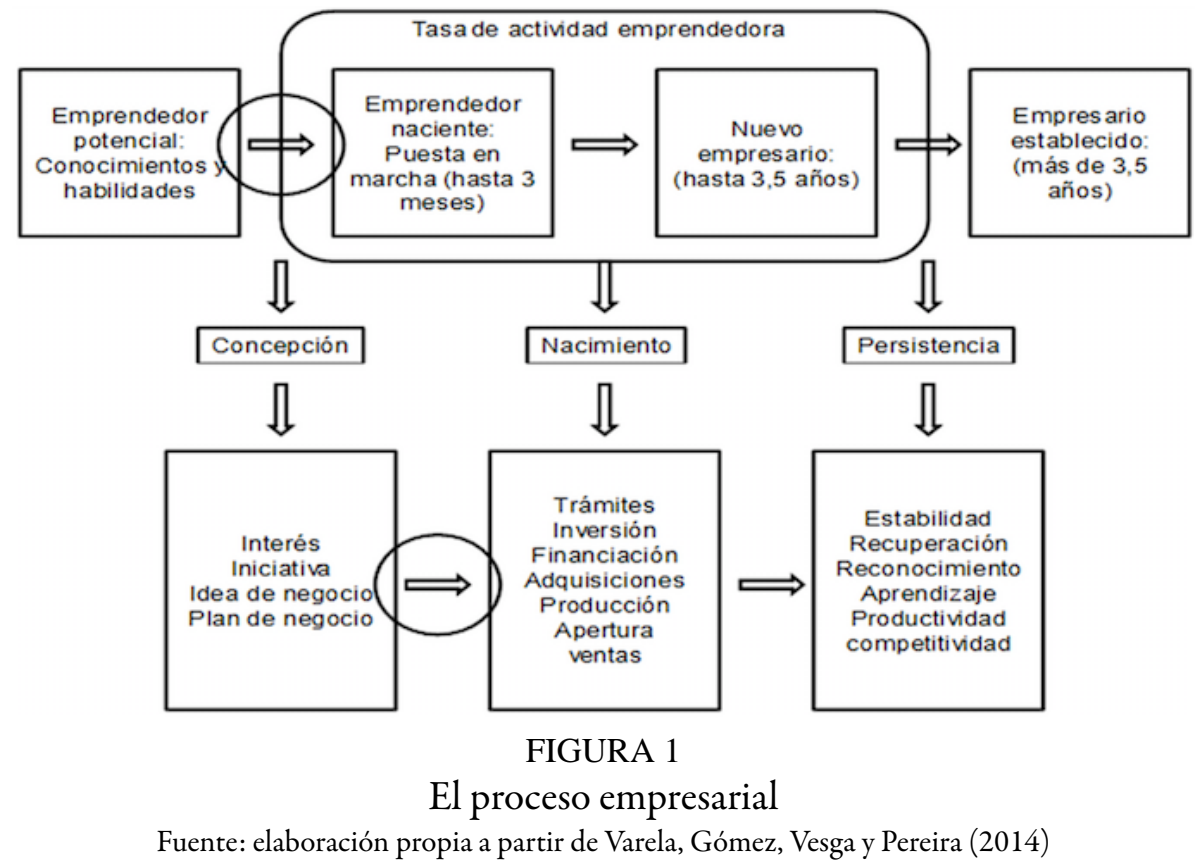

De acuerdo con lo anterior, se puede afirmar que el proceso de creación de una empresa involucra una serie de etapas que incluyen la sensibilización, la gestación de la idea y del plan de negocio, la gestión de los recursos, la legalización, el montaje, la puesta en marcha de la iniciativa y su consolidación. En ese contexto, el negocio se crea con fines económicos y de bienestar social para el emprendedor, para su familia y para su entorno (Arango, 2011). 
El espíritu empresarial es el factor clave del desarrollo económico. Determina con qué rapidez y precisión un sistema económico identifica y responde a las oportunidades de beneficios inherentes a las situaciones de desequilibrio. Por lo tanto, genera una mayor coordinación de las actividades económicas en un momento dado y aumenta la tasa de crecimiento de la economía a lo largo del tiempo. (Harper, 2003) ${ }^{2}$

Quien crea la empresa es el empresario. La siguiente tabla es un resumen de las principales definiciones del término empresario que presenta Rodrigo Varela en su libro Innovación Empresarial, arte y ciencia en la creación de empresas (2001).

TABLA 1

El empresario

\begin{tabular}{|c|c|}
\hline Autor & Definición de empresario \\
\hline Say (1827) & $\begin{array}{l}\text { El empresario es un agente que reúne y combina medios de producción } \\
\text { para elaborar productos. Además, recupera su inversión y la utilidad que } \\
\text { busca cuando vende tales productos. }\end{array}$ \\
\hline Elis y Hess (1937) & $\begin{array}{l}\text { Es quien planea, organiza y administra una empresa para su utilidad } \\
\text { personal. Asimismo, asume riesgos y se enfrenta a circunstancias } \\
\text { imprevistas e incontrolables. }\end{array}$ \\
\hline Schumpeter (1950) & $\begin{array}{l}\text { El empresario es el agente fundamental del cambio en las actividades de } \\
\text { producción. Su función es reformar, innovar y crear nuevos productos, } \\
\text { nuevos procesos o nuevas formas de producir antiguos productos. }\end{array}$ \\
\hline McClelland (1961) & $\begin{array}{l}\text { El empresario es alguien que ejerce control sobre los medios de } \\
\text { producción. Además, produce más de lo que consume con el fin de } \\
\text { venderlo o intercambiarlo, y lograr un beneficio propio. }\end{array}$ \\
\hline Drucker (1986) & $\begin{array}{l}\text { El trabajo del empresario es maximizar las oportunidades. En } \\
\text { consonancia, se ocupa de ellas, en tanto que las entiende como las } \\
\text { actividades que se deben realizar, y no como las actividades bien } \\
\text { realizadas. En ese sentido, aquello último constituye la función principal } \\
\text { del gerente. }\end{array}$ \\
\hline Shapero (1985) & $\begin{array}{l}\text { El empresario debe tener como atributos la toma de iniciativa, asi como } \\
\text { las capacidades de la organización y de la reorganización de los } \\
\text { mecanismos sociales y económicos competentes. Tales atributos, al igual } \\
\text { que las aptitudes para asumir riesgos calculados y la autoconfianza, son } \\
\text { idóneos para convertir los recursos y situaciones en hechos prácticos. }\end{array}$ \\
\hline Baty (1990) & $\begin{array}{l}\text { El éxito empresarial depende de la mente empresarial, que constituye } \\
\text { una actitud poco compasiva pero no 'feroz'. Envuelve la confianza en la } \\
\text { intuición y en la racionalidad; la capacidad de pensar táctica y } \\
\text { estratégicamente, asi como la capacidad de integrar muchos hechos en un } \\
\text { plan de acción. }\end{array}$ \\
\hline Ronstadt (1984) & $\begin{array}{l}\text { Ronstadt definió la función empresarial como el proceso dinámico de } \\
\text { creación de riqueza incremental. En ese sentido, la riqueza es creada en } \\
\text { contraprestación por el riesgo que asumen los individuos en términos de } \\
\text { capital, tiempo y compromiso personal. }\end{array}$ \\
\hline Timmons (1999) & $\begin{array}{l}\text { El espiritu empresarial es definido como la habilidad de crear y construir } \\
\text { algo a partir de casi nada: es un acto creativo propio del género humano. } \\
\text { Consiste, entonces, en tomar riesgos calculados y luego hacer todo lo } \\
\text { posible para evitar la falla; es percibir oportunidades; es identificar, } \\
\text { acumular y controlar recursos. }\end{array}$ \\
\hline Veciana (1997) & $\begin{array}{l}\text { Los empresarios crean empresas, puestos de trabajo y riqueza. En suma, } \\
\text { son personas que reunen cualidades pocos comunes a comparación de las } \\
\text { necesarias para seguir instrucciones de otros. }\end{array}$ \\
\hline
\end{tabular}

Fuente: elaboración propia a partir del trabajo de Varela (2001)

Con base en las anteriores definiciones, Varela (2001) plantea una definición ecléctica del empresario en los siguientes términos:

El empresario es la persona o conjunto de personas capaces de percibir una oportunidad de producción o de servicio, y ante ella formula [...] una decisión de consecución y asignación de recursos naturales, financieros, tecnológicos y humanos necesarios para poder poner en marcha la empresa, que además de crear valor incremental para la economía, genera trabajo para él y muchas veces para otros. 
Según Drucker (1985, citado en Formichella, 2002), en el proceso empresarial se necesitan conocimientos, habilidades, actitudes, aptitudes y atributos específicos; sin embargo, ante todo se requiere trabajo para lograr la formación y el desarrollo que el proceso exige. La acción empresarial es una conducta más que un rasgo del carácter, y su base es conceptual y teórica: no meramente intuitiva.

TABLA 2

El proceso empresarial

\begin{tabular}{l|l}
\hline Autor & Definición de empresario \\
\hline Shapero (1985) & $\begin{array}{l}\text { El proceso empresarial es definido por el evento empresarial, el cual es a } \\
\text { su vez delineado por la toma de iniciativa, la acumulación de recursos, la } \\
\text { administración, la autonomía relativa y la toma de riesgo. }\end{array}$ \\
\hline McClelland (1961) & $\begin{array}{l}\text { El impulso del espíritu empresarial, la aparición de nuevos empresarios y } \\
\text { la creación de nuevas empresas son los resultados de la articulación de la } \\
\text { motivación al logro, el proceso empresarial y el desarrollo económico. }\end{array}$ \\
\hline Ronstadt (1984) & $\begin{array}{l}\text { La perspectiva empresarial es resultado de la interacción del empresario } \\
\text { con el negocio y el entorno. Asi pues, el desarrollo empresarial } \\
\text { constituye un proceso dinámico y en permanente cambio, en el que el } \\
\text { empresario se ve influenciado por diversos eventos, pensamientos y } \\
\text { acciones. }\end{array}$ \\
\hline Timmons (1999) & $\begin{array}{l}\text { El líder empresarial es el eje en el proceso de creación de una empresa. } \\
\text { En el proceso empresarial, articula la oportunidad, el equipo empresarial } \\
\text { y los recursos. }\end{array}$ \\
\hline Gibb (1988) & $\begin{array}{l}\text { El proceso empresarial es el resultado de la combinación de motivación y } \\
\text { determinación; idea y mercado; habilidades y recursos. }\end{array}$ \\
\hline
\end{tabular}

Fuente: elaboración propia a partir del trabajo de Varela (2001)

\section{El método}

La investigación fue de tipo exploratorio y descriptivo. A partir de ambas acciones que envuelven la pesquisa, se identificaron la naturaleza y causas del problema, y se describieron los factores esenciales para la creación de empresas. Se utilizó el método analítico y de síntesis para conocer las características generales del emprendimiento, y para articular entre sí los factores relevantes en la creación de empresas. Para el muestreo se implementó la técnica de conveniencia o selección. Como metodología de investigación se utilizó el estudio de caso: un procedimiento que se inserta en la perspectiva cualitativa de la investigación social. El método estadístico se complementa de manera idónea con el estudio de caso: dicha metodología provee las bases adecuadas para la identificación de los casos particulares, y para la posterior generación de resultados que serán objeto de tabulación, análisis y procesamiento. La información se recolectó por medio de la aplicación de un cuestionario a veinticuatro emprendedores que lograron crear nuevas empresas con el acompañamiento del Área de Apoyo a la Creación de Empresas del Parque del Emprendimiento, en la ciudad de Medellín entre 2008 y 2010.

\section{Resultados y discusión}

A continuación, se muestran gráficas y descripciones de los resultados de un cuestionario que fue aplicado a un grupo de veinticuatro emprendedores participantes en el programa. Dicho grupo recibió orientación y 
acompañamiento por parte del Área de Apoyo a la Creación de Empresas del Parque del Emprendimiento en la ciudad de Medellín, entre 2008 y 2010.

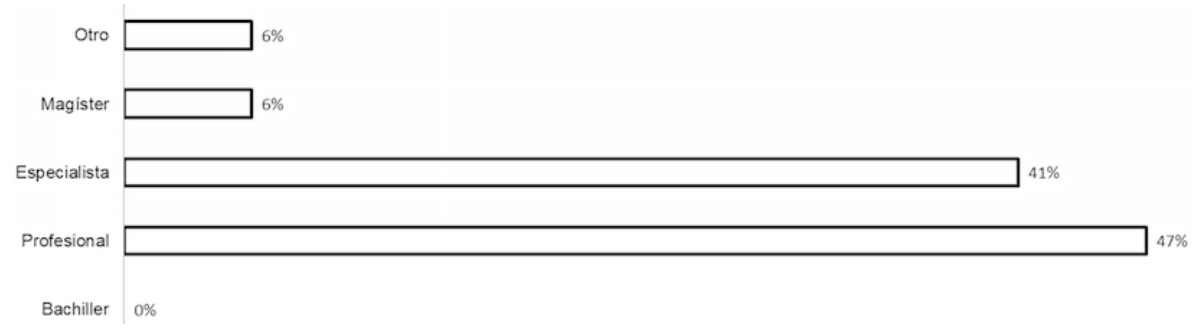

FIGURA 2

Nivel de formación de los emprendedores

Fuente: resultados de investigación

En los emprendedores que asisten al Parque del Emprendimiento en busca de apoyo para la creación de sus nuevas empresas, predomina la formación profesional, seguida muy cerca por los emprendedores con estudios de especialización. El factor educacional concuerda con lo expresado por Drucker (1986, citado en Varela, 2001), quien plantea que, si bien para el proceso de creación de empresas se necesitan conocimientos, habilidades, actitudes, aptitudes y atributos, sobre todo se requiere trabajo para lograr la formación y el desarrollo que el proceso exige. Para Drucker, la acción empresarial es una conducta más que un rasgo del carácter, y su base es conceptual y teórica, no meramente intuitiva; por tanto, dicha acción empresarial puede estudiarse y aprenderse. El emprendedor necesita educación, formación y capacitación (Valenciano \& Uribe, 2009) para iniciar y consolidar un proceso de creación de una nueva empresa. Como lo plantea Varela (2001) cuando se refiere a los mitos del empresario: la educación es la única forma mediante la cual el empresario mejora sus habilidades de gestión y eleva las probabilidades de supervivencia y crecimiento de su empresa. Algo similar expresan por su parte las investigaciones de Escandón y Hurtado (2014), por una parte, y las de Franco y Urbano (2010), por otra, así como la de Plaza (2014). Asimismo, el desarrollo de la actividad empresarial permite al empresario adquirir habilidades y destrezas que traen como efecto una mayor eficiencia en el manejo y sostenimiento de la compañía (Texis, Ramírez, \& Aguilar, 2016).

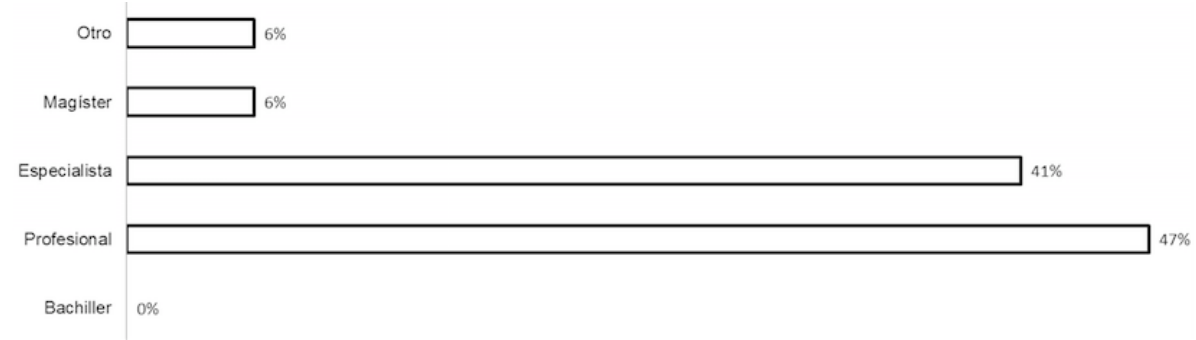

FIGURA 3

Motivo del emprendimiento empresarial

Fuente: resultados de investigación

La iniciativa personal es el factor más relevante a la hora de comenzar la creación de una nueva empresa, seguido de la oportunidad de poner un nuevo negocio. Contrario a lo que comúnmente se suele creer, el desempleo no es un impulsor del emprendimiento, así como tampoco lo es la tradición familiar. Esta iniciativa personal concuerda con lo que Shapero (1985, citado en Varela, 2001) denomina el evento empresarial, que es la condición individual, empresarial y social para que se dé la creación de una nueva empresa; imperativo que está definido por cinco características interrelacionadas entre sí: iniciativa, recursos, administración, autonomía y riesgo. Dicha perspectiva concuerda además con la teoria de motivación al logro de MacClelland (1961); la teoría de cambio de trayectoria vital, de Shapero (1985, citado en Varela, 2001), y la etapa de motivación del modelo de formación de empresas de Varela (2001). Nadie obliga a un emprendedor a crear su 
propia empresa: es su propia iniciativa (Franco y Urbano, 2010), o es el resultado de un impulso interior que lo moviliza en tal sentido. Para Valenciano \& Uribe (2009), la idea de constituir una empresa debe ser el fruto de una profunda reflexión y del convencimiento de ser emprendedor. Más que de los incentivos externos, el proceso de creación de una empresa se origina por la percepción que el individuo tiene de sus objetivos y capacidades (Marulanda, Montoya, \& Vélez, 2014).

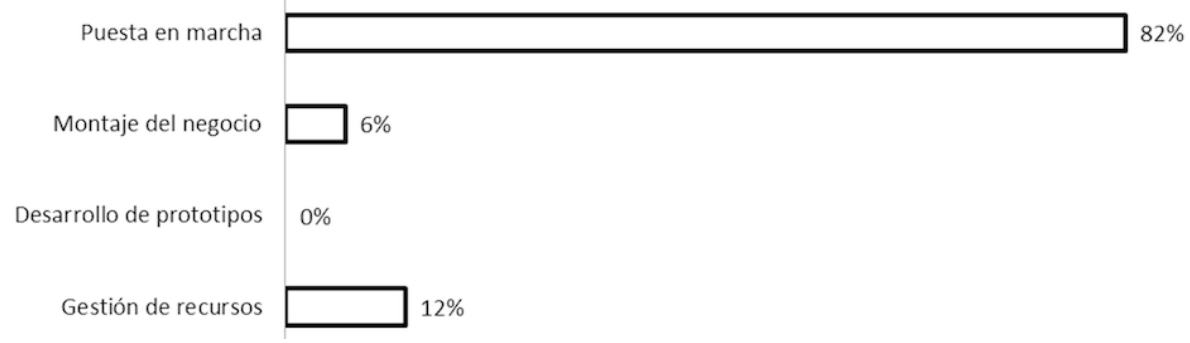

FIGURA 4

Estado actual del emprendimiento

Fuente: resultados de investigación

Entre los emprendedores encuestados, la puesta en marcha del negocio es la fase predominante, seguida de lejos por las fases de gestión de recursos y de montaje del negocio. La puesta en marcha del negocio coincide con el modelo de formación de empresas de Varela (2001), a saber: la etapa de nacimiento del negocio, en la cual se realizan los trámites legales, se adquieren materias primas y equipos, y se inician las labores de producción y venta de productos o servicios. A continuación sigue la fase de puesta en marcha del negocio, la cual es crucial para el proceso de formación de la empresa. En esta etapa, el emprendedor tiene que afrontar dificultades y obstáculos que pueden poner en entredicho su carrera empresarial. El espíritu empresarial y el apoyo de las redes de contactos son cruciales para el éxito de este proceso. La fase de la puesta en marcha coincide además con la etapa de nacimiento que planteó Gibb (1988, citado en Varela, 2001) en su modelo de formación de empresas: paradigma que está compuesto de seis etapas y que es muy apropiado para los emprendedores de los países en vías de desarrollo. Estas etapas son: (1) la adquisición de motivación y generación de ideas; (2) la validación de la iniciativa; (3) la definición del tamaño viable y de los recursos necesarios; (4) la negociación de la entrada; (5) el nacimiento, y (6) la supervivencia de la empresa.

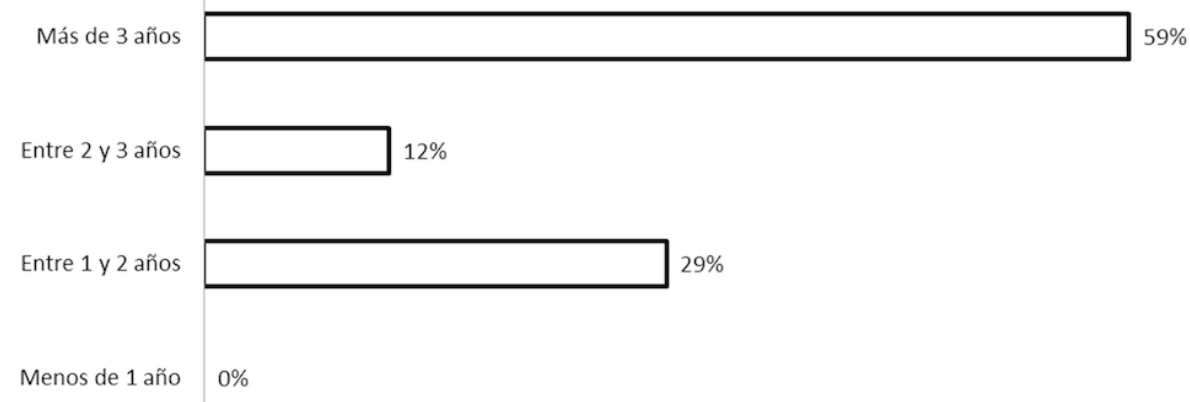

FIGURA 5

Tiempo invertido en el emprendimiento

Fuente: resultados de investigación

El tiempo invertido predominante es el mayor a 3 años. Dicho plazo coincide con la preponderancia de la fase de puesta en marcha del negocio que, según los expertos, dura entre tres y cinco años. Posteriormente, se da paso a las fases de consolidación y aceleración, que se caracterizan por la apertura de nuevos mercados y el desarrollo de nuevos productos. En el proceso de creación de empresas, la inversión de más de tres años coincide con la etapa de nuevo empresario que presentan Varela et al. (2014) del estudio GEM: Colombia, 
en particular el texto denominado "Dinámica empresarial colombiana". Este tiempo también coincide con la etapa de supervivencia del negocio del modelo de formación de empresas que plantea Varela (2001): fase en la que se pasa del estado de pérdida al de utilidad. En el contexto de la ciudad de Medellín en particular, es importante hacer un llamado a unir esfuerzos entre emprendedores y entidades de apoyo que apunten a reducir dicho plazo. No obstante, a lo largo del tiempo el individuo puede desarrollar competencias y habilidades para tener un mayor control y un mejor manejo de sus actividades empresariales (Matuoka, Aretes, Giovanetti, Hashimoto \& Bedê, 2010).

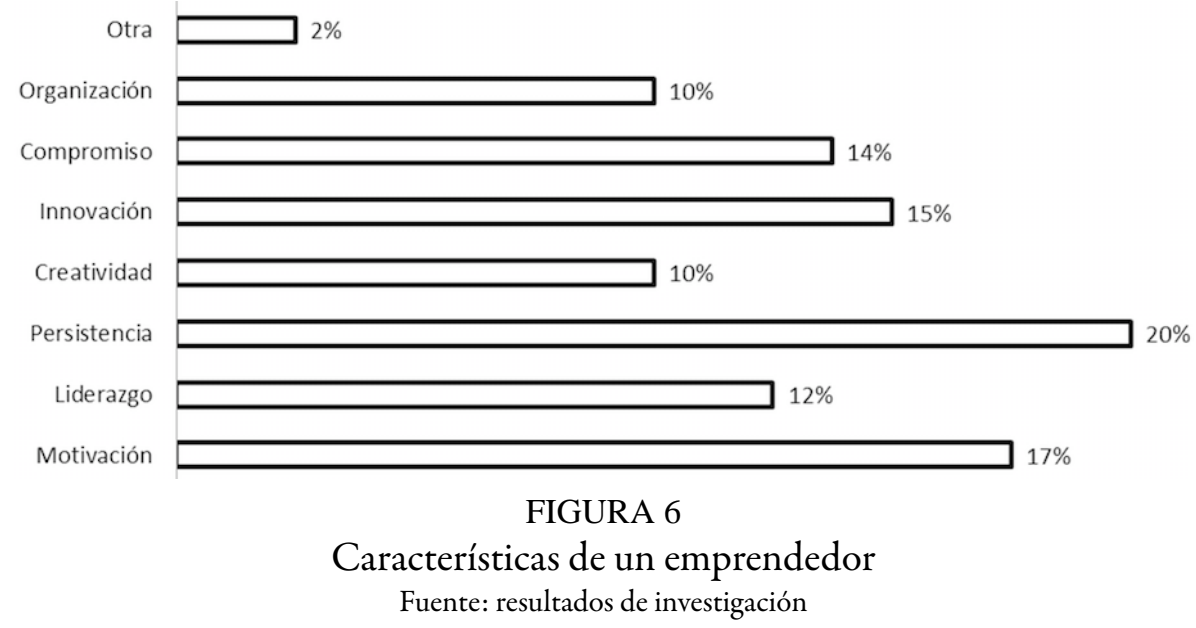

De acuerdo con los individuos encuestados, las principales características que debe tener un emprendedor son la persistencia, la motivación, la innovación y el liderazgo. Aunque en menor escala, también se destaca la importancia de la creatividad y la organización. Las anteriores características también están presentes en las listas que presentan en sus estudios Varela (2001) y Timmons (1999, citado en Varela, 2001); compendios mucho más amplios que han sido agrupado por sus autores en varias categorías. Sobre los mitos del empresario, Varela plantea que, aunque muchas compañías ejemplares requirieron una invención o tecnologías avanzadas, la gran mayoría de las empresas nuevas se basan en tecnologías convencionales o conocidas. De lo anterior se puede inferir que, si bien es cierto que las nuevas tecnologías, al igual que la invención y la innovación, son necesarias para el proceso de creación de empresas, la característica esencial para el emprendimiento es el espíritu empresarial. Como lo plantea McClellan (1961, citado en Varela 2001) en su teoría sobre la motivación al logro, dicho rasgo se asocia más fácilmente con la persistencia y la motivación por alcanzar el logro de crear la nueva empresa, que con la creatividad y la innovación. Conclusiones similares se derivan de las investigaciones de Escandón y Hurtado (2014), por una parte, y las de Franco y Urbano (2010), por otra, al igual que del trabajo de Plaza (2014). En ese contexto cabe añadir que el emprendimiento es mucho más que la innovación sistemática, pues involucra estrategias emprendedoras y principios de gestión empresarial que son necesarios, en el mismo grado, en empresas establecidas y en nuevas compañías (Drucker, 2004). 


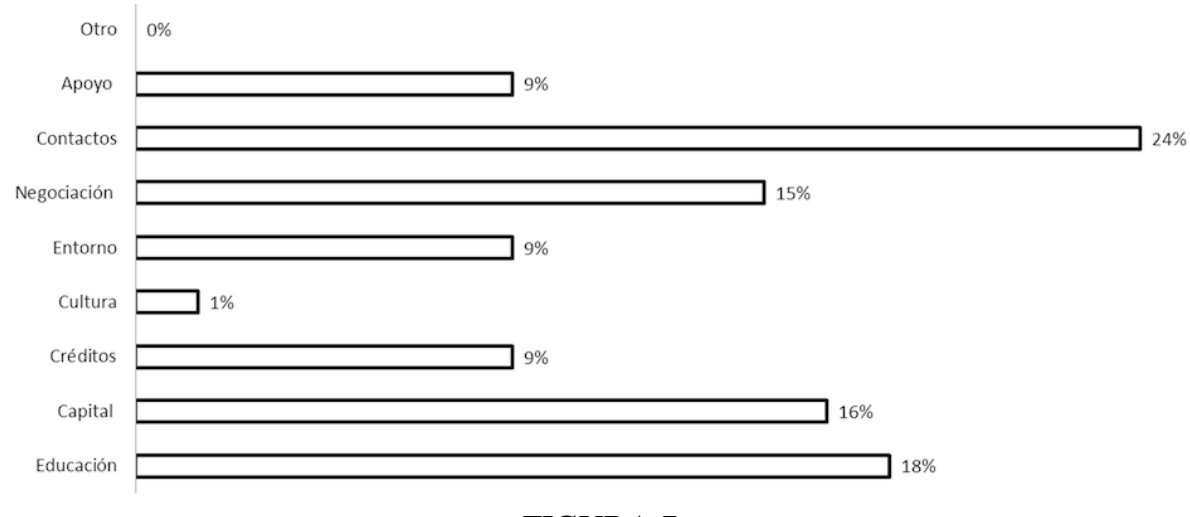

FIGURA 7

Factores relevantes del emprendimiento

Fuente: resultados de investigación

El factor más relevante al momento de emprender un nuevo negocio son los contactos que pueda tener el emprendedor. Por su parte, la educación, el capital y la capacidad negociadora son aspectos preponderantes para el emprendimiento de negocios. En tanto, los créditos, el manejo del entorno y el apoyo son asuntos que tienen una menor relevancia a la hora de emprender un nuevo negocio. Dichos factores son también tenidos en cuenta por Vesper (1990, citado en Varela, 2001), quien plantea que en todo negocio están presentes cinco elementos: el conocimiento técnico, la oportunidad, los contactos personales, los recursos y los clientes con pedido. De acuerdo con dicha lista, Vesper señala que el éxito de todo negocio está asociado ante todo con los contactos o relaciones que se desenvuelvan con proveedores, así como con los clientes e instituciones que ha construido el empresario. Asimismo, el autor plantea que para las personas jóvenes esta es una de las limitaciones más grandes en lo que atañe a la gestión empresarial, en otras palabras: el tener o carecer de estas relaciones empresariales crea una diferencia sustancial en la facilidad de gestionar la empresa. Adicionalmente, la noción de red guarda relación con los sistemas productivos locales que se ha venido interpretando, en términos de los distritos industriales marshallianos (Boix \& Galletto, 2005; Brunet \& Alarcón, 2004; Climent, 1997). Por último, la articulación del emprendedor y la empresa con el entorno es un factor esencial del emprendimiento empresarial (Álvarez, Galindo \& Valencia, 2010).

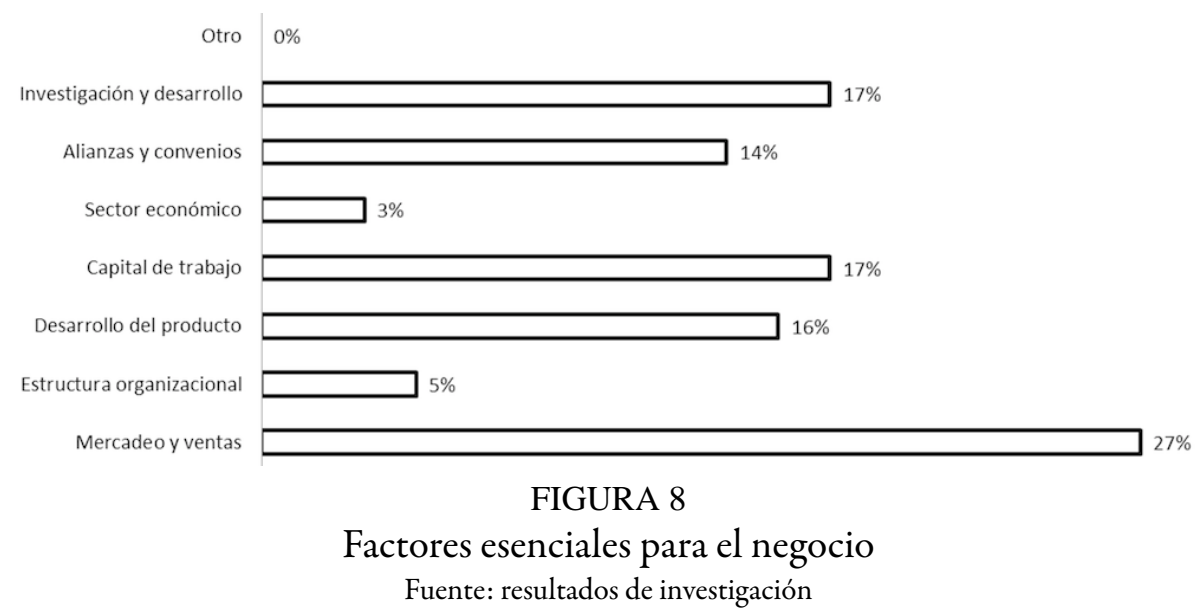

Con respecto al negocio en tanto tal, el factor de mayor relevancia es el que corresponde al mercadeo y las ventas. Dicho aspecto es seguido con relativa cercanía por otros como la investigación y el desarrollo; el capital de trabajo, y el desarrollo de nuevos productos. En la siguiente escala se sitúan las alianzas y los convenios. Por su parte, el sector económico y la estructura organizacional tienen poca relevancia en el negocio. En suma, los emprendedores ratifican lo postulado por Vesper (1990, citado en Varela, 2001) en su modelo de los cinco 
elementos, quien plantea que un negocio solo tiene la posibilidad de ser exitoso cuando los clientes potenciales se vuelven clientes reales que compran y pagan. Adicionalmente, de acuerdo con el autor, un negocio solo tiene futuro cuando logra identificar y captar nuevos clientes sin perder a los clientes antiguos, pues se produce para vender, y si no hay clientes con pedido no tiene sentido producir y la empresa no tiene razón de ser.

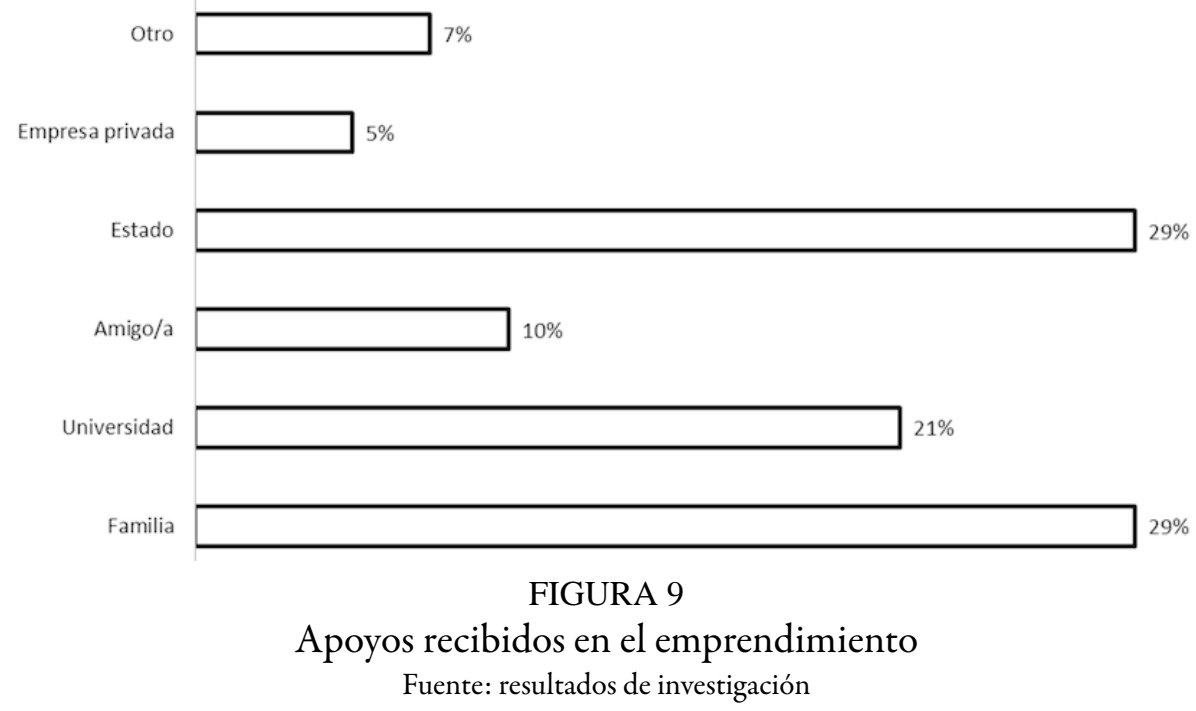

Las mayores fuentes del apoyo que han recibido los emprendedores encuestados han sido el Estado y sus familiares. En ese contexto, la universidad se destaca como una fuente de apoyo importante para el emprendimiento de nuevos negocios. En contraste, es evidente la poca relevancia que la empresa privada tiene en dichos procesos. De acuerdo con lo anterior, Varela (2001) plantea que hay empresarios que inician su carrera empresarial un año después de graduarse, pues han resuelto de forma temprana el dilema planteado por Shapero (1985, citado en Varela, 2001) sobre el cambio de trayectoria vital. Un segundo grupo lo hace después de los ocho años, pues corresponde a profesionales que han iniciado otra carrera como preparación para el quehacer empresarial. Por último, el tercer grupo, el cual inicia dichas actividades después de los once años sin haberse preparado específicamente para ellas, es el de mayor vulnerabilidad pues puede abandonar fácilmente la carrera empresarial. No obstante, sin importar cuál sea el momento en que el emprendedor decida iniciar una carrera empresarial, para que tenga éxito es fundamental que cuente con el apoyo de su cónyuge o de su familia. Del mismo modo es importante contar con una red de apoyo externa al negocio conformada por proveedores y clientes, así como por instituciones públicas y privadas. El asesoramiento empresarial es un cimiento fundamental para los procesos de creación y puesta en marcha de la empresa (Sanchis, 2001; Valenciano \& Uribe, 2009). 


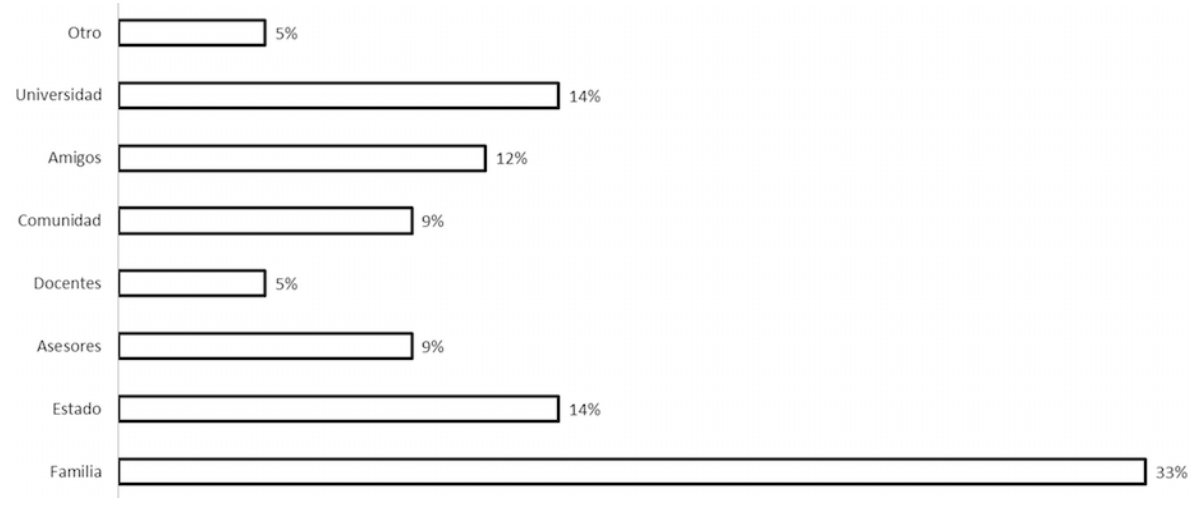

FIGURA 10

Agentes influyentes en el emprendimiento

Fuente: resultados de investigación

En ese escenario, el agente que tiene mayor influencia en el emprendimiento de los nuevos negocios es la familia del emprendedor, aspecto que se sitúa muy por encima de los demás agentes de influencia. En contraste, el Estado, la universidad y los amigos del emprendedor tienen una menor influencia. Asimismo, en una menor escala se destaca la influencia de los asesores, así como la de la comunidad y la de los docentes. En el contexto de las condiciones sociales, culturales y económicas de la ciudad de Medellín --cuya ancestralidad empresarial se remonta a los pioneros que forjaron la llamada cultura paisa, caracterizada por su pujanza y determinación para emprender industrias y proyectos continuos de desarrollo social y económico-, la familia es y sigue siendo el agente de mayor influencia en los procesos descritos. La familia le apuesta todo al esposo o al hijo o hija que desea cambian, explorar y arriesgar para iniciar una carrera empresarial. Ante el éxito, el nuevo empresario recibe impulso, y ante el fracaso recibe apoyo y acompañamiento. En la cultura paisa, contexto cultural del emprendimiento de la ciudad de Medellín, la familia ha sido, es y seguirá siendo el principal agente de influencia empresarial. De hecho, existen condiciones que rodean al emprendedor y que influyen positiva o negativamente en el crecimiento empresarial (Cuervo, 2004; Cuervo, Ribeiro \& Roig, 1979; EOI, 2006; Incyde, 2001).

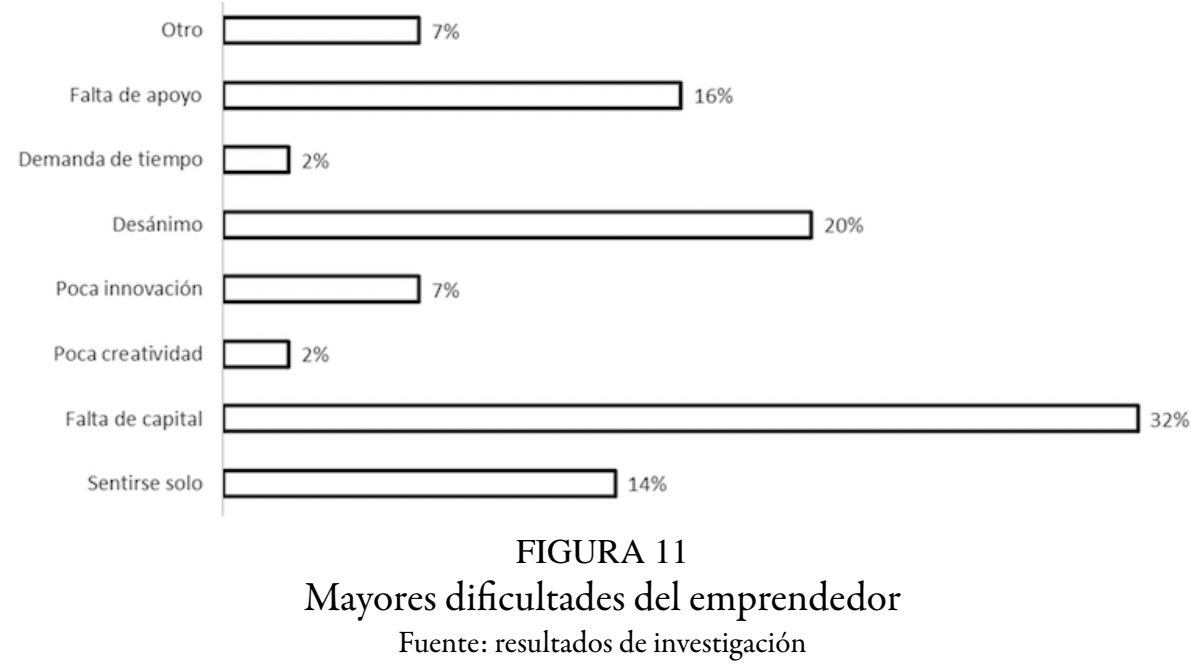

La falta de capital es el factor que supone mayores dificultades para quienes emprenden la creación de nuevos negocios. El desánimo, la ausencia de apoyo y el sentimiento de soledad son factores de menor relevancia; sin embargo, tienen gran importancia. En ese sentido, de acuerdo con la pesquisa expuesta, la falta de innovación y de creatividad son aspectos con poca relevancia en el emprendimiento de un nuevo negocio. Con respecto a la falta de capital, Varela (2001) es categórico al afirmar que esta corresponde a la 
ausencia de capacidad empresarial, pues ante la escasez de recursos para iniciar el montaje de su empresa entre los cuales están los financieros-, el nuevo empresario debe tener la habilidad suficiente para conseguirlos y sostenerlos. Dado que la falta de dinero es la base de uno de los mayores mitos empresariales, Varela (2001) plantea -en concordancia con Veciana (2005) - que esa constituye la disculpa más frecuente de quienes no son empresarios para explicar su falta de creatividad, decisión e iniciativa. En ese sentido, el autor arguye que una de las habilidades empresariales más importantes es la capacidad de identificar y conseguir distintos tipos de recursos, entre ellos, los financieros. Plantea, además, que muchas veces la abundancia de dinero, más que constituir una ayuda, es un perjuicio, pues generalmente en condiciones de afluencia no se valoran las decisiones, y se incurre en grandes desperdicios económicos. En concordancia, la carencia de un perfil emprendedor, la falta de actitudes para el proceso, el poco conocimiento, la indisposición ante la incertidumbre y la falta de innovación son limitaciones asociadas con los problemas del individuo para emprender un negocio (Cardona, Vera \& Tabares, 2008).

\section{Conclusiones}

La acción de constituir una nueva empresa es una interiorización del emprendedor. El individuo es el eje del emprendimiento, en un contexto en el cual el espíritu empresarial es la fuerza interior que lo lleva a materializar su deseo de ser independiente económicamente, mediante la creación de una nueva empresa. En consecuencia, el espíritu empresarial es innato en el emprendedor, y sin él no es posible que logre el objetivo de poner en funcionamiento una idea de negocio mediante la creación de una nueva compañía. El emprendimiento es una acción solitaria, difícil, retadora, llena de obstáculos y de riesgos para el emprendedor y su familia.

En tal escenario, la ausencia de innovación no se relaciona con ninguna carencia de espíritu empresarial. Este constituye por su parte la fuerza interior que permite la creación de una empresa. Asimismo, con sus componentes humanos y técnicos, la educación es un factor relevante para la tarea de emprender una nueva compañía. En consonancia, la ausencia de este factor constituye un obstáculo para el emprendimiento. De la misma manera, cabe destacar que el emprendimiento surge como una iniciativa personal más que por oportunidad o por necesidad.

En suma, las principales características del emprendedor son la persistencia, la motivación, la innovación, el liderazgo y el compromiso. Asimismo, los factores de mayor relevancia para el éxito de un emprendimiento son los contactos, la educación, el capital y la capacidad de negociación. Por su parte, los aspectos de mayor importancia para el sostenimiento del negocio son las duplas conformadas por el mercadeo y las ventas; la investigación y el desarrollo, y las alianzas y los convenios, al igual que el capital de trabajo y el desarrollo de productos. En otro plano, la fuente de apoyo más influyente para el emprendedor es la familia, seguida del Estado, la universidad y los amigos. La investigación también demuestra que las mayores dificultades que tiene que sobrellevar el emprendedor son la falta de capital, la ausencia de apoyo y el sentimiento de soledad, así como los estados de desánimo que pueden sobrevenir ante los múltiples desafíos que envuelve la creación de una empresa. Por último, cabe señalar que la falta de innovación y de creatividad no constituyen una dificultad para el emprendedor en su proceso de idear, implementar y operar una nueva empresa.

\section{Recomendaciones}

La principal recomendación se dirige hacia el estimulo de la innovación y la creatividad: aspectos esenciales para la constitución de nuevas empresas. Si bien tal es la misión de los programas institucionales que impulsan y apoyan el emprendimiento, su ausencia no debe suponer un factor de descarte del emprendedor y de su idea de negocio. En consonancia, cabe también sugerir el diseño de técnicas de selección de emprendedores 
con verdadero espíritu empresarial, independientemente de que su idea inicial de negocio tenga o no el factor innovador. Asimismo, vale la pena sugerir que los programas institucionales que impulsan y apoyan el emprendimiento se centren más en el espíritu empresarial del emprendedor que en su idea y plan de negocio. Del mismo modo, es menester desmontar los concursos de emprendimiento y destinar los recursos que se han utilizado en ellos en la financiación de los proyectos de empresa cuyos líderes cuenten con un verdadero espíritu empresarial: personas que necesitan capital de trabajo, especialmente en las etapas de planeación y montaje de las nuevas empresas.

Asimismo, es pertinente sugerir que -especialmente en las instituciones de educación superior- la cátedra de emprendimiento se utilice solamente para dar a conocer qué es el emprendimiento, y no para iniciar procesos de sensibilización. Además, es recomendable que se creen laboratorios de empresa en donde solo participen los emprendedores seleccionados por su espíritu empresarial en las instituciones educativas que impulsan y apoyan el emprendimiento. De modo similar, es recomendable que el apoyo que brindan el Estado y las unidades de emprendimiento de las instituciones educativas se traduzca ante todo en recursos financieros y en el desarrollo de prototipos, así como en la identificación e investigación de mercados, y no en actividades de sensibilización y motivación dirigidas hacia el emprendimiento. Finalmente, cabe alentar al Estado y a las unidades de emprendimiento de las instituciones educativas para que creen fondos de capital destinados al las actividades descritas: recursos que sirvan para financiar líderes con verdadero espíritu empresarial.

\section{Referencias}

Álvarez, A. H., Galindo, M. Á., \& Valencia, P. (2010). Determinantes de la consolidación empresarial en España. Revista Europea de Dirección y Economía de la Empresa, 19, $49-59$.

Arango, J. J. (2011). Identificación de los factores que tienen mayor relevancia en la creación de una nueva empresa en la ciudad de medellin desde la perspectiva del emprendedor empresarial. Caso: Parque del Emprendimiento (tesis de maestría). Universidad de Medellín, Medellín, Colombia.

Boix, R. \& Galletto, V. (2005). Sistemas locales de trabajo y distritos industriales marshallinaos en España. Barcelona: Departamento de Economía Aplicada - Universidad Autónoma de Barcelona. Recuperado de http://www.eca p.uab.es/RePEc/doc/wpdea0514.pdf

Brunet, I. \& Alarcón, A. (2004). Teorías sobre la figura del emprendedor. Papers, 73, 81-103.

Cardona, M., Vera, L. D., \& Tabares, J. (2008). Las dimensiones del emprendimiento empresarial: la experiencia de los programas cultura e y fondo emprender en Medellín. Cuadernos de Investigación, 69, 72. https://doi.org/1 $0.2139 /$ ssrn.2459621

Climent, E. L. (1997). Sistemas productivos locales y distritos industriales: el caso de España. Boletín de la Asociación de Geógrafos Españoles, 27(1997), 91-106.

Cuervo, Á. G. (2004). Dinámica empresarial y consolidación sectorial. Universia Business Review, (1), 96-105. Recuperado de http://search.ebscohost.com/login.aspx?direct=true\&db=a9h\&AN=21684380\&lang=es\&sit $\mathrm{e}=$ ehost-live

Cuervo, Á., Ribeiro, D., \& Roig, S. (1979). Entrepreneurship\#: conceptos, teoría y perspectiva. Madrid: Universidad Complutense de Madrid.

Real Academia Española (1726-1739). Diccionario de Autoridades. Recuperado de http://web.frl.es/DA.html

Real Academia Española [RAE] (2012). Diccionario de la Real Academia de la lengua Española (DRAE). Recuperado de http://dle.rae.es/?id=bJiPomE

Drucker, P. F. (2004). La disciplina de la innovación. Harvard Business School Publishing Corporation, 3-7. Recuperado de http://www.sela.org/media/2366647/r-la-disciplina-de-la-innovacion.pdf

Drucker, P. F. y Maciariello, J. A. (1954). Management. New York: Harper Collins E-Books. Recuperado de http://w ww.amazon.ca/exec/obidos/redirect?tag=citeulike09-20\&path=ASIN/0887306136 
EOI (2006). Factores que influyen en la creación y consolidación de empresas en Andalucia. Andalucía: EOI - Escuela de Negocios.

Escandón, D. M. y Hurtado, A. A. (2014). Factores que influyen en el desarrollo exportador de las pymes en Colombia. Estudios Gerenciales, 30(131), 172-183. https://doi.org/10.1016/j.estger.2014.04.006

Formichella, M. M. (2002). El concepto de emprendimiento y su relación con la educación, el empleo y el desarrollo local. Instituto Nacional de Tecnoogía Agropecuaria, Buenos Aires, Colombia. Recuperado de ftp://ftp.unicauca.edu.co/Facultades/FIET/Materias/Gestion_tecnologica/2005/ Clase\%2012/Nuevos/emprendydesarrollolocal.pdf

Franco, M. Á. \& Urbano, D. P. (2010). El éxito de las Pymes en Colombia: un estudio de casos en el sector salud. Estudios Gerenciales, 26(114), 77-96. https://doi.org/10.1016/S0123-5923(10)70103-0

Harper, D. A. (2003). Foundations of entrepreneurship and economic development. London and New York: Routledge. Recuperado de http://tmtfree.hd.free.fr/albums/files/TMTisFree/Documents/Economy/libertarianismo/dhf oeaed.pdf

Incyde (2001). Factores para consolidar una empresa. Madrid: Unión Europea Fondo Social Europeo.

Kirzner, I. M. (1998). El empresario: lecturas de economía política. Revista Libertas, 29(Octubre de 1998). Recuperado de http://www.eseade.edu.ar/files/Libertas/16_3_Kirzner.pdf

Marulanda, F. Á., Montoya, I. A., \& Vélez, J. M. (2014). Teorías motivacionales en el estudio del emprendimiento. Pensamiento \& Gestión, (36), 204-236. https://doi.org/10.14482/pege.36.5571

Matuoka, F. M., Aretes, R., Giovanetti, S. L., Hashimoto, M., \& Bedê, M. A. (2010). A sobrevivência de empresas nascentes no estado de São Paulo: um estudo sobre capital humano, capital social e práticas gerenciais. Rausp, 45(4), 343-355. https://doi.org/10.1016/S0080-2107(16)30466-6

Morales, M. A. \& Segoviano, L. E. (2016). Una perspectiva económico-institucional de la toma de decisiones: solución de problemas en situación de incertidumbre. Investigación Económica, 75(298), 57-75. https://doi.org/10.1016 /j.inveco.2016.11.002

MacClelland, D. (1961). The Achieving Society. Princeton: Van Nostrand.

Plaza, J. J. (2014). La innovación en el ámbito de la supervivencia y consolidación de nuevas empresas. Recuperado de https://www.researchgate.net/profile/Juan_Jose_Plaza-Angulo2/publication/242604318_LA_INNOVA CION_EN_EL_AMBITO_DE_LA_SUPERVIVENCIA_Y_CONSOLIDACION_DE_NUEVAS_EMP RESAS/links/0c96052e8e127a74f4000000.pdf

Sanchis, J. R. (2001). Creación y consolidación de empresas mediante el crecimiento en red: su aplicación al desarrollo local. Revista DyO, 25(Febrero de 2001), 4-25. Recuperado de http://www.revistadyo.com/index.php/dyo/art icle/view/217/217

Tarapuez, E. C., Zapata, J. A., \& Agrenda, E. M. (2008). Knight y sus aportes a la teoría del emprendedor. Estudios Gerenciales, 24(106), 83-98. Recuperado de https://www.icesi.edu.co/revistas/index.php/estudios_gerenciales /article/view/254/252

Texis, M. F., Ramírez, M. U., \& Aguilar, J. G. (2016). Microempresas de base social y sus posibilidades de supervivencia. Contaduría y Administración, 61(3), 551-567. https://doi.org/10.1016/j.cya.2015.04.001

Valenciano, J. \& Uribe, J. T. (2009). Emprendimiento de la economía social y desarrollo local: promoción de incubadoras de empresas de economía social en Andalucía. CIRIEC-España, Revista de Economía Pública, Social $Y$ Cooperativa, (64), 5-33. Recuperado de http://www.ciriec-revistaeconomia.es/banco/6401_De_Pablo_y_U ribe.pdf

Varela, R. V., Gómez, L., Vesga, R., \& Pereira, F. (2014). Dinámica empresarial colombiana. Bogotá, Cali y Barranquilla: Universidad de los Andes, Universidad Javeriana e Icesi.

Varela, R. V. (2001). Innovación empresarial: arte y ciencia en la creación de empresas. Bogotá: Pearson.

Veciana, J. M. (2005). La creación de empresas, un enfoque gerencial. Barcelona: Colección Estudios Económicos. Recuperado de http://www.caixabankresearch.com/documents/10180/54279/ee33_esp.pdf 


\section{Notas}

1 El Diccionario de Autoridades fue el primer diccionario en ser editado por la Real Academia Española (RAE), que fue fundada en 1713. Dicho documento fue publicado en seis tomos entre los años 1726 y 1739. La edición del año 1732 incluyó la definición del término emprendedor.

2 Todas las traducciones del inglés corresponden al autor.

\section{Licencia Creative Commons CC BY 4.0}

Para citar este artículo: Arango Benjumea, J. J. (2017). Identificación de factores esenciales para la creación de empresas desde la perspectiva del emprendedor: el caso del Parque del Emprendimiento. Cuadernos de Contabilidad, 18(45), 110-124. https://doi.org/10.11144/Javeriana.cc18-45.ifec 